\title{
The Pneumococcus: Epidemiology, Microbiology, and Pathogenesis
}

\author{
Birgitta Henriques-Normark ${ }^{1}$ and Elaine I. Tuomanen ${ }^{2}$ \\ ${ }^{1}$ Department of Microbiology, Tumor, and Cell Biology, Karolinska Institutet, SE-171 77 Stockholm, Sweden \\ ${ }^{2}$ Department of Infectious Diseases, St. Jude Children's Research Hospital, Memphis, Tennessee 39105 \\ Correspondence: elaine.tuomanen@stjude.org
}

The pneumococcus is the classic Gram-positive extracellular pathogen. The medical burden of diseases it causes is amongst the greatest in the world. Intense study for more than 100 years has yielded an understanding of fundamental aspects of its physiology, pathogenesis, and immunity. Efforts to control infection have led to the deployment of polysaccharide vaccines and an understanding of antibiotic resistance. The inflammatory response to pneumococci, one of the most potent in medicine, has revealed the double-edged sword of clearance of infection but at a cost of damage to host cells. In virtually every aspect of the infectious process, the pneumococcus has set the rules of the Gram-positive pathogenesis game.

Streptococcus pneumoniae (the pneumococ-

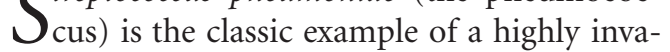
sive, Gram-positive, extracellular bacterial pathogen. It is a major cause of morbidity and mortality globally causing more deaths than any other infectious disease. At highest risk are the smallest children and the elderly with $\sim 1$ million children below 5 years of age dying yearly (Centers for Disease Control 2008). Pneumococcal diseases range from mild respiratory tract mucosal infections such as otitis media and sinusitis to more severe diseases such as pneumonia, septicemia, and meningitis. It is estimated in the United States that about $5 \%$ of those that get pneumococcal pneumonia die from the disease. The corresponding figure for septicemia is $20 \%$ and for meningitis, lethality is as high as 30\% (Tomasz 1997). Although pneumococcus can cause lethal diseases, it is more commonly a quiescent colonizer of the upper respiratory tract where up to $60 \%$ of small children may carry pneumococci in the nose asymptomatically (Henriques-Normark et al. 2003; Nunes and Sa-Leao 2005).

Medically, the three major bacterial pathogens of children have historically been the pneumococcus, Haemophilus, and meningococcus. All three are naturally transformable and undergo autolysis in the stationary phase. They share the same progression of disease from the nasopharynx to blood and brain and use phosphorylcholine on their surfaces to bind to the same series of receptors in the pathway of innate invasion (Thornton et al. 2010). This uniquely shared pattern of disease and microbial biology makes understanding this group of enormous importance. Whereas vaccination has succeeded in dramatically reducing disease caused by

Editors: Pascale Cossart and Stanley Maloy

Additional Perspectives on Bacterial Pathogenesis available at www.perspectivesinmedicine.org

Copyright (C) 2013 Cold Spring Harbor Laboratory Press; all rights reserved; doi: 10.1101/cshperspect.a010215

Cite this article as Cold Spring Harb Perspect Med 2013;3:a010215 
Haemophilus and meningococcus, pneumococcus remains a poorly controlled outlier. The huge number of pneumococcal serotypes (compared to the small number for the other two pathogens) remains the main challenge in developing strategies to control this global pathogen.

\section{EPIDEMIOLOGY}

Pneumococcal infections are thought to spread from person to person via droplets/aerosols and nasopharyngeal colonization is a prerequisite for pneumococcal disease. The carriage rate peaks around $2-3$ years of age and diminishes thereafter to $<10 \%$ in the adult population. However, adults with small children at home may have a higher carriage rate. The bacteria enter the nasal cavity and attach to the nasopharyngeal epithelial cells and may then either stay as a colonizer or spread further to other organs, such as the ears, sinuses, or via bronchi down to the lungs and then potentially penetrate the mucosal barrier to enter the blood stream and/or cross the blood-brain barrier to cause meningitis (Fig. 1).

Tracking the global or local spread of pneumococci is commonly done by serotyping of the capsular polysaccharide. So far, at least 93 different capsular structures/serotypes have been described. Certain serotypes are most commonly found in young children, such as types $6 \mathrm{~B}, 9 \mathrm{~V}$, $14,19 \mathrm{~F}$, and 23F. A comparison of invasive disease isolates and carriage isolates from the same region during the same time period suggests that virulence differs depending on the capsular serotype (Brueggemann and Peto 2004; Sandgren et al. 2004, 2005). Some serotypes, such as 1 and $7 \mathrm{~F}$, are more prominent in invasive disease (they have a high invasive disease potential) whereas other types are mainly involved in carriage. However, only rare serotypes cause only carriage. Patients infected with serotypes with a

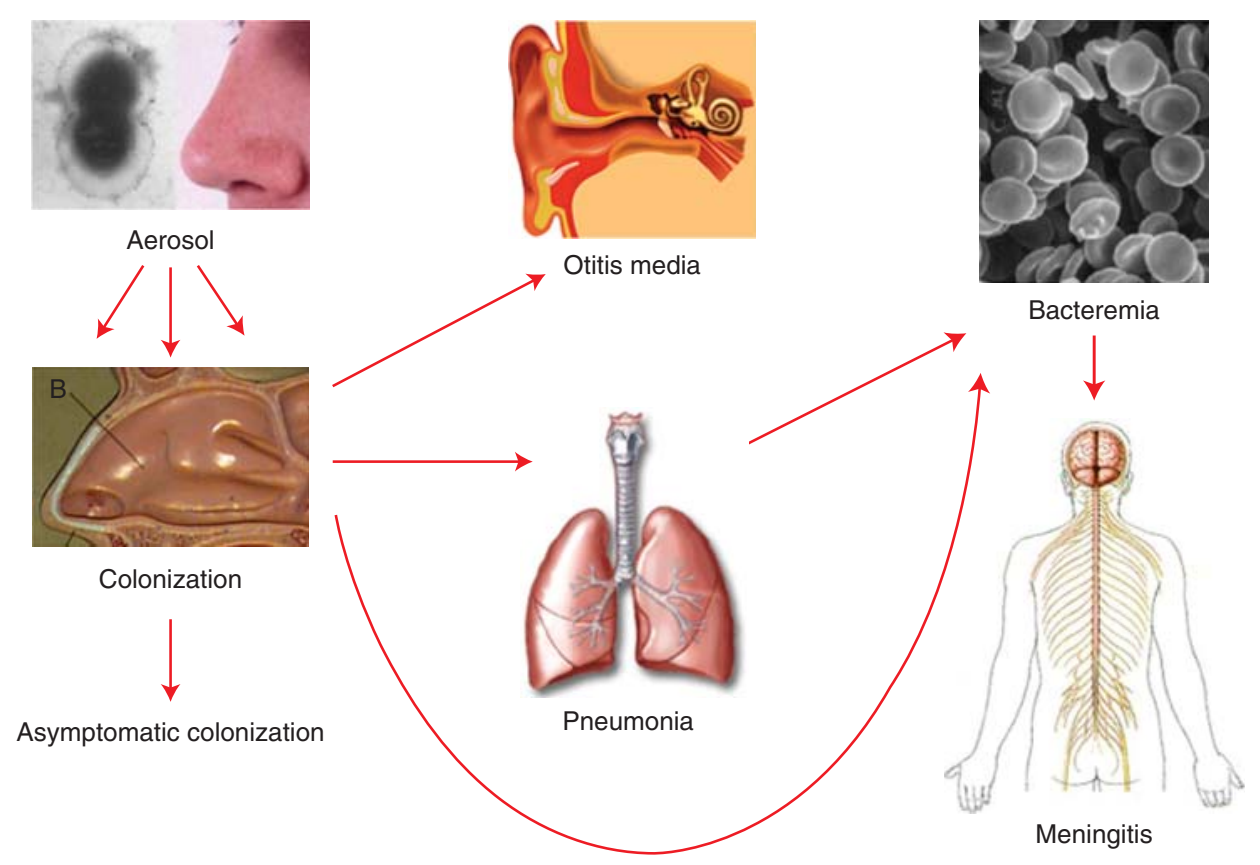

Figure 1. Progression of pneumococcal disease. Spread by aerosol, pneumococci are harbored in the nasopharynx. This interaction most commonly leads to clearance and serotype-specific immunity. Progression to otitis media is very common in children. Invasive disease involves spread to the lungs and bloodstream. The most serious development is meningitis. This series of invasive steps is a pattern shared by the three major bacterial pathogens of children (pneumococcus, Haemophilus, and meningococcus) and is driven by a very basic interplay between innate invasion and innate immunity. 
low invasive disease potential more often had an underlying disease before the pneumococcal infection as compared to patients infected with serotypes with a high invasive disease potential (Sjöström et al. 2006). However, the highest mortality rates were found in patients infected with serotypes of a lower invasive disease potential, such as types 3,6B, and 19F (Sandgren et al. 2004).

Since pneumococci naturally take up DNA from other bacteria and potentially switch capsular serotype, other methods than serotyping need to be used to study genetic relationships between clinical pneumococcal isolates, i.e., clonal types. Such molecular techniques include PFGE (pulsed field gel electrophoresis), whereby bacterial chromosomal DNA is cleaved using restriction enzymes and then put on a pulsed field gel separating the bands depending on their charge and size. Another sequenced based method is MLST (multilocus sequence typing) in which seven housekeeping genes are sequenced and the strains are assigned a sequence type (ST) depending on allelic variations. PFGE is more discriminatory than MLST and can be used also to study outbreaks. Furthermore, genomic comparisons using whole genome-based microarrays have shown that MLST can be used as a good method to estimate genome content (Dagerhamn et al. 2008).

Pneumococcal serotypes causing invasive disease have been shown to differ between geographic areas and the distribution is also dependent on the time period studied. This is especially important because current pneumococcal vaccines are based on a limited number of capsular polysaccharides. For decades, a 23-valent vaccine consisting of only polysaccharides was used in the elderly and immunocompromised individuals. As this vaccine is not immunogenic in the smallest children, newer vaccines are now used in which proteins are coupled to the polysaccharides to get a more T-cell-dependent immune response. For technical reasons and because of high costs, only a limited number of polysaccharides have been included so far in the conjugate vaccines $(7,10$, and recently 13 serotypes). The serotypes have been chosen because they are the dominant serotypes causing inva- sive disease in the United States, a choice that means they are not well matched to other geographic areas with different serotype distribution. A review by Lin compiling data from studies performed in the Asia-Pacific region shows that the potential coverage rate for the sevenvalent conjugate vaccine ranges from $>70 \%$ to $<50 \%$ (Lin 2010). The seven-valent vaccine was introduced into the childhood vaccination program in the United States in year 2000. Since then a tremendous decrease has been observed in vaccine-related invasive pneumococcal disease in children (Whitney et al. 2003). Also, a reduction in carriage of vaccine types has been noticed as well as a herd immunity effect in the adult population. However, an increase of invasive disease caused by nonvaccine types and clonal expansion of nonvaccine clones of certain serotypes has now been observed. It is worrisome that pneumococci may circumvent the vaccine by capsular switch events and that the immune pressure by the vaccine may select for minor serotypes not included in the vaccines. Therefore, pneumococcal molecular epidemiology must be followed thoroughly after vaccine introduction to detect possible adverse effects of vaccination, such as an increase of nonvaccinetype diseases.

For decades, the standard treatment of pneumococcal infections has been penicillin. However, a widespread increase of pneumococci resistant to most antibiotics (except for vancomycin) has been witnessed. Data from the European networks EARSS (www.rivm.nl/ earss) on the rates of resistance to certain antibiotics among invasive disease isolates in $\mathrm{Eu}$ rope indicate an increasing trend of resistance to both penicillin and erythromycin. Multiresistant clonal types have emerged even in countries with a low frequency of resistance, such as in Sweden. Molecular typing of antibiotic resistant isolates shows that some pneumococcal clonal types are more prone to be spread globally. One such successfully spread clonal type is ST156, carrying resistance to penicillin and trimethoprim sulfamethoxazole, originated in Spain and spread to other countries facilitated by a pathogenicity islet encoding a pilus-like structure on the surface of pneumococci, shown 
to be important for colonization in a mouse model (Barocchi et al. 2006; Sjöström et al. 2007). The introduction of pneumococcal vaccines into the childhood vaccination programs in many countries is also expected to affect resistance rates. However, the experiences differ somewhat because some areas observe a decreased rate of resistance after vaccination whereas others do not see the same effect because they also have an increase of nonvaccine types. In the United States an expansion of serotype 19A was observed with resistance to many antibiotic drugs, creating treatment problems for common infections.

\section{MICROBIOLOGY}

\section{The Surface}

The pneumococcal surface is covered by a polysaccharide capsule that overlays the cell wall comprised of peptidoglycan and teichoic acid. Although the peptidoglycan has the classical Gram-positive structure of $\mathrm{N}$-acetylglucosamine, $N$-acetylmuramic acid, and a lysine-containing stem peptide, the teichoic acid is unusual in containing a ribitol phosphate backbone and covalently attached phosphorylcholine (PCho) (Bean and Tomasz 1977). A nutritional requirement for choline is unique to $S$. pneumoniae. PCho serves as a docking station for noncovalent linkage of many pneumococcal proteins to the bacterial surface (Rosenow et al. 1997). In addition, the LPxTG motif is targeted by sortases that covalently link proteins to the cell wall (Löfling et al. 2011).

The surface composition of the bacteria varies between two distinct states: transparent and opaque colony types (Weiser et al. 1994). The precise mechanism of this phase variation is unclear but its impact is to aid in evading host defenses, such as C-reactive protein (CRP), which targets PCho, and leukocytes in blood while promoting attachment to host cells in the nasopharynx. The transparent phenotype dominates in the nasopharynx and expresses less capsule and less of the choline binding protein PspA, but more of the choline binding proteins CbpA and LytA autolysin (see below). In contrast, the opaque phase predominates in the blood and is characterized by increased capsular polysaccharide and PspA and less CbpA. Opaque bacteria also produce a greater biofilm and are more invasive for lungs and brain (Trappetti et al. 2011).

\section{Capsule}

The pneumococcal capsule has played a major role in the history of many medical discoveries and basic science tenets. In 1928, Griffith reported genetic exchange in bacteria when nonencapsulated, avirulent derivatives were transformed to a virulent, encapsulated phenotype following co-infection in mice (Griffith 1928). Avery, MacLeod, and McCarty then determined that Griffith's "transforming principle" was DNA and hence the discovery of the genetic material (Avery et al. 1944). The polysaccharide capsules are antiphagocytic and sterically hinder the access of leukocytes to complement fixed on the underlying cell wall. The capsule locus, transcribed as a single operon, shows a similar organization in all strains with genes encoding a specific capsule type flanked by genes common to all types.

\section{Pili}

Pili are multimeric filamentous surface structures composed of subunit proteins with LPxTG motifs recognized by sortases and attached to the cell wall. Two pathogenicity islets encoding pili, PI-1 and PI-2, are involved in adhesion (Barocchi et al. 2006; Bagnoli et al. 2008). PI-1, encoded by the rlrA accessory region, has been shown to influence colonization, virulence, and the inflammatory response in mouse challenge models. This pilus is composed of three covalently attached structural proteins in which $\operatorname{RrgB}$ is the major stalk protein, and $\operatorname{RrgC}$ and RrgA are ancillary proteins decorating the pilus shaft and tip. $\operatorname{RrgA}$ is the major adhesion and its three-dimensional structure has recently been solved (Nelson et al. 2007; Izoré et al. 2010). The role of the three pilus associated sortases in the assembly of the pilus has also been explored in which both Sortase B and Sortase $\mathrm{C}$ have been suggested to act as pilus subunit 
polymerases, whereas Sortase D is required for wild-type focal presentation of the pilus at the cell surface (Fälker et al. 2008).

\section{Transformation}

Pneumococci are naturally transformable, a state permissive for DNA uptake that arises for an entire population of pneumococci at one time in a highly regulated manner. The first description of quorum sensing is attributed to the induction of pneumococcal transformation (Tomasz 1965). The competence stimulating peptides (CSP1 and 2) are released and act externally on the two component system ComD/E. Binding of the cognate CSP induces the ComD histidine kinase to phosphorylate ComE, the response regulator, activating the $\operatorname{com} A B$ and com $C D E$ operons resulting in a wave of competence that proceeds throughout the pneumococcal culture. This surge of early competence gene expression is followed by a second wave of expression of 16 late competence genes found in eight operons bearing the common combox. Many genes in this second wave are required for DNA binding and uptake.

\section{Surface Proteins}

Surface-exposed pneumococcal proteins are marked by one of three sequence motifs: the LPxTG cell wall anchor, a choline-binding domain, or a lipoprotein domain. The LPxTG bridge covalently anchors a class of more than a dozen degradative enzymes and pilus proteins to the cell wall. The choline binding protein (Cbp) family is unique to $S$. pneumoniae and the $\sim 12$ members share a 20 amino acid choline-binding domain repeated 3-9 times at the carboxyl terminus (Rosenow et al. 1997). Key proteins belong in this class. The LytA autolysin hydrolyses peptidoglycan and is critical for cell division. Pneumococcal surface protein A (PspA) inhibits complement deposition and activation, binds lactoferrin, and interferes with uptake into phagocytes. Cbp's A, D, E, and G play roles in adherence. CbpA is an adhesin that presents a specific motif for binding to the polymeric immunoglobulin receptor on the nasopharyngeal mucosa and a second motif for binding the laminin receptor at the blood-brain barrier (Hammerschmidt et al. 1997; Orihuela et al. 2009). Both interactions enable bacterial translocation across their respective barriers. CbpA also binds complement $\mathrm{C} 3$ and factor $\mathrm{H}$.

\section{Genome}

The complete annotated 2.16 Mbps genome of S. pneumoniae encoding 2236 predicted proteins was first published in 2001 (Tettelin et al. 2001). Sequence analysis (www.sanger.ac. $\mathrm{uk} /$ resources/downloads/bacteria/streptococcus-pneumoniae.html or www.biomedcentral. com/1471-2180/11/25) indicates a nutritionally fastidious, lactic acid fermenting, facultative anaerobe with a $\mathrm{G}+\mathrm{C}$ content of $40 \%$. As pneumococcus lacks the TCA cycle, it depends on fermentation of carbohydrates for energy and can catabolize 14 different sugars. Onethird of the predicted coding regions have no known function and a third of the genome varies sufficiently between strains to be considered to encode noncore functions. With the ability to naturally take up DNA and undergo transformation, the genome is exceptionally highly variable. Up to $10 \%$ of genes show altered sequences between isolates and 3\%-5\% of the genome shows insertion sequences and truncations. The number of DNA repeat regions is at the top of all available genomes and likely contributes to plasticity. Next generation sequencing has shown that pneumococci carried in the nasopharynx progressively accumulate recombination events indicative of the sequential transfer of DNA in vivo (Hiller et al. 2010). Sequencing of hundreds of globally dispersed strains of a single serotype 23F lineage showed large-scale recombination events varying in size between $3 \mathrm{bp}$ and 72,038 bp (Croucher et al. 2011). Important major changes resulted in the frequent spread of antibiotic resistance and a shift in capsular serotype from $23 \mathrm{~F}$ to $19 \mathrm{~A}$, indicating escape under vaccine pressure.

Large-scale identification of $S$. pneumoniae virulence determinants at the genomic level has been attempted. Signature-tagged mutagenesis (STM) (Lau et al. 2001; Hava and Camilli 2002) 
and Tn-Seq (van Opijnen et al. 2009) have used libraries of mutants to screen for survival in animal models. Gene expression in vivo and in various tissues has been performed at the transcriptome level using microarrays, deep RNA sequencing, and tiling array studies (Sorek and Cossart 2010). The genomic content of invasive versus noninvasive strains or clonotypes has suggested that the swapping of cassettes of "regions of diversity" changes infection dynamics leading to organ specific virulence (Orihuela et al. 2004). These methods have also revealed complex regulatory pathways, including at least 13 two-component systems (Paterson et al. 2006) and many sRNAs that act in the absence of Hfq (Mann et al. 2012).

\section{COLONIZATION BIOLOGY}

The ecological niche for pneumococci is the nasopharynx of small children. Carriage rates decrease with age and duration of carriage is longer in younger $(\sim 43 \mathrm{~d})$ than older children $(\sim 25 \mathrm{~d})$ (Högberg et al. 2007). When the bacteria enter the nasal cavity, the negatively charged capsule protects the bacteria from being trapped in the mucous and the bacteria can reach the epithelial surface. At the surface, transparent variants express a thinner capsule and better adherence during initial colonization (Weiser et al. 1994).

Many surface proteins affect nasopharyngeal colonization. A prominent example is CbpA (also called PspC or SpsA) that binds to the polymeric immunoglobulin receptor ( $\mathrm{pIgR}$ ) and promotes adherence and uptake of bacteria into nasopharyngeal cells (Hammerschmidt et al. 1997; Zhang et al. 2000; Braathen et al. 2006). Other adhesins include CbpG (Mann et al. 2006), CbpD (Gosink et al. 2000), and LPxTG proteins such as the pilus proteins and IgA protease (Weiser et al. 2003). The formation of a biofilm is promoted by $\mathrm{Psr} P$ which mediates bacterial aggregation and intraspecies adherence (Sanchez et al. 2010).

Enzymes, including NanA (neuraminidase), BgaA ( $\beta$-glucosidase), and SrtH ( $\beta$ - $N$-glucosaminidase), affect colonization by cleaving terminal sugars from human glycoconjugates, thereby potentially exposing receptors for adherence.
NanA also promotes biofilm formation and the development of otitis media (Tong et al. 2000; Munoz-Elias et al. 2008). Hyaluronidase helps to spread bacteria in the tissue and components like PavA and enolase interact with extracellular matrix proteins such as fibronectin and plasminogen (Bergmann et al. 2001; Kolberg et al. 2006). The serine protease HtrA also strongly influences nasopharyngeal colonization (Sebert et al. 2002).

An experimental colonization study in humans showed that carriage induces both mucosal and systemic immunoglobulin production and that the response is strain and type specific (McCool and Weiser 2002). Prevention of colonization involves Th17-cell adaptive responses (Lu et al. 2008) whereas progression against invasive disease is mediated by antibody (Cohen et al. 2011). Mouse studies indicate that clearance requires bacterial phagocytosis by CCR2bearing monocyte/macrophages. Recruitment of these cells and production of anticapsular antibodies depend on the induction of CCL2 from macrophages that involves LysM fragmentation of peptidoglycan, uptake of the fragments, and sensing by Nod2 (Davis et al. 2011). Thus, peptidoglycan hydrolases such as LysM, LytB (glucosaminidase), LytC (lyzosyme), and Pce or CbpE (esterase) may affect colonization by programming immune responses (Bergmann and Hammerschmidt 2006).

An important aspect of the epidemiology of pneumococcal colonization is the common occurrence of co-infections. It is widely recognized that mortality during influenza outbreaks is due in large part to secondary pneumococcal pneumonia. Colonization with pneumococci concurrently with influenza leads to a synergistic type-1 interferon response with decreased clearance of bacteria from the nasopharynx and increased pneumonia (Nakamura et al. 2011).

\section{HOST-BACTERIA INTERACTIONS IN THE COURSE OF INVASIVE DISEASE}

\section{Pneumonia: Common Invasion Strategy}

As bacteria enter the lower respiratory tract, the initiation of pneumonia requires escape from 
mucous defenses and bacterial migration into the alveolus. Neuraminidase cleaves mucin and the absence of NanA attenuates pneumonia (Berry and Paton 2000). NanA also uncovers glycoconjugates, such as $\mathrm{N}$-acetylgalactosamine $\beta 1-3$ galactose, on host cells that provide sites for loose bacterial attachment. Interference with this step by neuraminidase inhibitors, such as oseltamivir, blocks the synergy in pneumonia between influenza and pneumococcus.

Firm adherence of bacteria to the alveolar epithelium and subsequent replication and initiation of host damage responses lead to the classic evolution of lobar pneumonia. The interaction of secreted products and cell surface-anchored bacterial components with the alveolar epithelium and innate immune defenses drives this process. The pore-forming toxin pneumolysin and hydrogen peroxide released in copious amounts by the bacteria disrupt the alveolar epithelium and edema fluid accumulates in the alveolar space (Canvin et al. 1995). Lipoteichoic acids, lipoproteins, and an array of proteins associated with the bacterial surface further amplify interactions with the host. During this early host response, bacteria gain firm adherence to the alveolar epithelium using several protein adhesins, including the histidine triad family of lipoproteins, LPxTG proteins, choline-binding proteins, and pili (Löfling et al. 2011). Proteins anchored by the LPxTG motif that bind the extracellular matrix include PavB (contains the highly repetitive SSURE domain), PfbA, PclA, and PsrP, an enormous serine rich protein (Jensch et al. 2010). Pili, encoded by PI-1 or PI2, bind bacteria to respiratory epithelial cells (Barocchi et al. 2006; Bagnoli et al. 2008). The Cbp family of proteins noncovalently attached to the phosphorylcholine determinant on the pneumococcal teichoic acid has a broad range of functions from proteases to cell wall-modifying enzymes to complement interactors to adhesins (Rosenow et al. 1997). CbpA in particular is important in binding pneumococci to host cells and PspA interacts with many innate host defense components.

Many respiratory pathogens have converged on a common strategy to advance mucosal disease to bacteremia. This process is termed "in- nate invasion" and is counteracted by the very early participants induced in innate immunity (Gould and Weiser 2002; Thornton et al. 2010) (Fig. 2). The key host receptor for innate invasion is the platelet-activating factor receptor (PAFr) (Cundell et al. 1995). Many respiratory pathogens decorate their surfaces with phosphorylcholine (PCho), an example of molecular mimickry as PCho is the ligand critical to the activity of the chemokine PAF. Binding of PCho to PAFr initiates uptake of the bacteria into a vacuole that is then trafficked across the host cell where bacteria can be released to seed the bloodstream (Radin et al. 2005). Mice lacking PAFr and mice treated with PAFr antagonists fail to progress from pneumonia to sepsis. The fundamental PCho-PAFr step in pathogenesis is countered by the innate acute phase response element C-reactive protein (CRP), which binds PCho and competitively inhibits the PAFr/ PCho-mediated bacterial invasion (Gould and Weiser 2002). Similarly, surfactant, which is rich in PCho, and an antibody to phosphorylcholine are competitive inhibitors of bacterial ligand binding to PAFr and CRP in the lungs (Briles et al. 1981). In this setup, innate invasion is counteracted by early response elements in innate immunity (Fig. 2).

Control of bacterial multiplication in the lung requires innate immune recognition of the pneumococccal pathogen-associated molecular patterns (PAMPs) that initiate recruitment of neutrophils and the accumulation of hemorrhagic debris as the hallmark of pulmonary consolidation. Pneumococcal peptidoglycan components induce signaling by TLR 2 and LPS binding protein (Yoshimura et al. 1999; Weber et al. 2003), PCho-bearing teichoic acid binds to PAFr (Cundell et al. 1995), and small intracellular peptidoglycan fragments are recognized by Nod2 (Girardin et al. 2003; Moreira et al. 2008 (Fig. 3). Pneumolysin is detected by TLR4 (Malley et al. 2003) and DNA is sensed by TLR9 (Albiger et al. 2007). The importance of the inflammatory response through the TLR pathways to activation of NF- $\kappa \mathrm{B}$ is highlighted by the altered disease susceptibilities in individuals with polymorphisms in this pathway (Brouwer et al. 2009). SNPs in NFKBIA, 


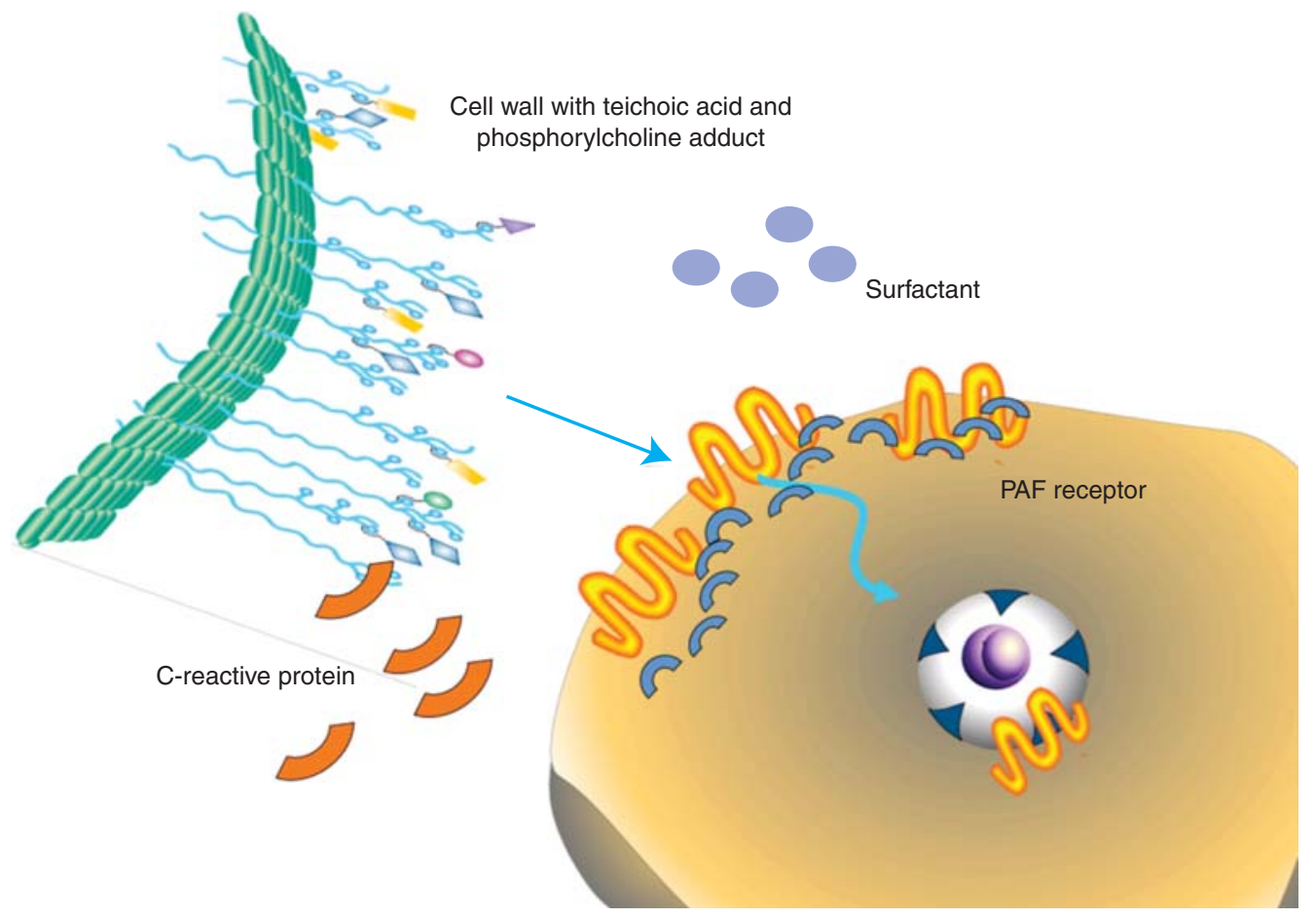

Figure 2. Innate invasion versus innate immunity. The majority of respiratory pathogens have phosphorylcholine (PCho) on their surfaces. PCho is on the cell wall teichoic acid of pneumococci (pictured as blue circles on cell wall surface extensions). PCho, by mimicking the host chemokine PAF, binds to the host cell plateletactivating factor receptor (PAFr) and its scaffold of $\beta$ arrestins, leading to the uptake of bacteria into a vesicle and transmigration across the epithelial or endothelial barrier. This simple invasion step is countered by innate immune elements. C-reactive protein binds to PCho on the bacteria and surfactant contains abundant PCho, both of which inhibit bacterial contact with the host cell.

NFKBIE, and TIRAP that lead to decreased inflammatory signaling show a protective effect, whereas impaired function of IRAK4 or NEMO increases susceptibility to pneumococcal infection. NF- $\mathrm{KB}$ signaling leads to the release of cytokines, particularly IL-6 and IL-1ß, which then induces neutrophil recruitment and macrophage activation. The lung is unique in enabling neutrophil recruitment specifically in response to pneumococcus in both a CD-11/CD-18 dependent and independent manner (Doerschuk et al. 2000). Although required for clearance of bacteria, the intense inflammation induced by neutrophils contributes to lung damage; neutropenia (although not a complete absence of neutrophils) may attenuate damage and improve outcome (Marks et al. 2007).
Pneumococcus secretes a potent cytotoxin, pneumolysin, which is a member of the cholesterol-dependent, pore-forming cytotoxin family (Boulnois et al. 1991; Rossjohn et al. 1997). It plays an important role in the respiratory tract, not only by lysing host cells but also by inhibiting the mucociliary beat of respiratory cells and separating epithelial cell tight junctions (Berry et al. 1989; Kadioglu et al. 2002). It similarly contributes to the pathogenesis of otitis media by cytotoxic effects on the hair cells of the cochlea in the middle ear (Sato et al. 1996). Pneumolysin activates the classical complement pathway (Brown et al. 2002) and may be recognized by TLR4, thereby evoking an inflammatory response (Malley et al. 2003). Pneumolysin has been shown to influence bacterial uptake into human dendritic cells, to inhibit cellular 
The Pneumococcus

PAFr
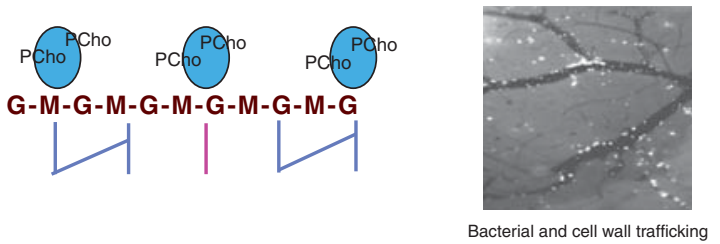

TLR2
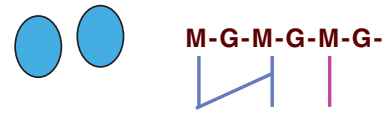

NOD2
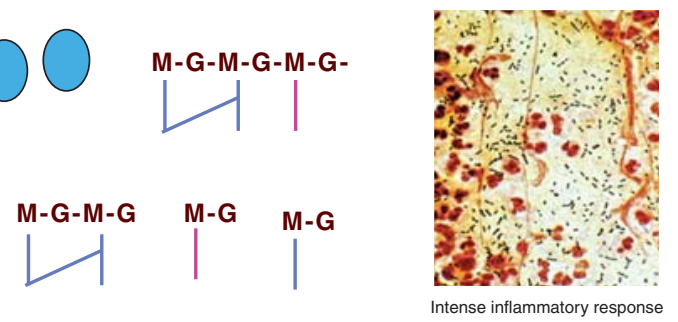

Figure 3. Pneumococcal cell wall PAMPs in disease progression. The cell wall of pneumococci is a major determinant of the course of disease. The interaction of PCho on the cell wall teichoic acid binds to PAFr and enables bacterial invasion of cells and transmigration across barriers. It also enables the cell wall itself to traffic to all organs (inset top: view through the cranial window of fluorescein-tagged cell wall pieces migrating from vasculature to brain). In the tissues, cell wall subcomponents generate intense inflammation by interacting with TLR2 and Nod2. Signaling through these receptors activates NF- $\kappa B$ pathways, cytokine, and chemokine production, leading to intense neutrophil recruitment (inset bottom: Gram stain of pneumococcus [blue] and neutrophils [red] in the lung).

activation and cytokine secretion, and to induce a caspase-dependent apoptosis (Braun et al. 2002). A nonfunctional pneumolysin, such as in some serotype 1 isolates, also influences inflammation induced by the interaction of bacteria and dendritic cells and might affect the development of diseases such as empyema (Littmann et al. 2009).

\section{Bacteremia}

The most important element in the development of high titer bacteremia is the pneumococcal polysaccharide capsule (Austrian 1981; Briles et al. 1992). Capsule is the key antiphagocytic element and antibody to capsule is opsonic and highly protective. Each of the $>90$ serotypes has a structurally unique polysaccharide and these vary in their antiphagocytic efficacy. Steric hindrance and negative charge determine the ability of a capsular type to inhibit surface deposition of complement, CRP, mannosebinding proteins, and antibodies that can bridge to receptors on the phagocytes (Briles et al. 1992). The amount of capsule is also important in that it is a phase variable trait and unencapsulated strains are essentially avirulent.

In addition to capsule, bacterial surface components interact with the complement cascade to impede complement deposition (Brown et al. 2002). PspA inhibits classical complement deposition and CbpA binds $\mathrm{C} 3$ and Factor H. Scavenger receptors, such as SR-A, macrophage receptor with collagenous structure (MARCO), and LOX-1, target the polyanionic teichoic acid and play a role in the clearance of bacteria. These interactions bridge bacteria to complement components or cellular phagocytic machinery.

\section{Meningitis: A Common Entry Path}

With high titer bacteremia, pneumococci come in contact with blood-brain barrier vascular endothelial cells. Crossing the tight junctions of this specialized endothelium enables entry into the cerebrospinal fluid and the brain parenchyma. Using pneumococcus as a probe, a common entry portal for meningeal pathogens was found for this site. Bacterial adhesins for Strep- 
tococcus pneumoniae, Haemophilus influenzae, and Neisseria meningitidis share a common epitope that permits binding to the endothelial 37/ $67-\mathrm{kDa}$ laminin receptor (LR) (Orihuela et al. 2009). This receptor is also targeted by many neurotropic viruses, implicating a common mechanism for the development of meningitis in general. In the case of pneumococci, the bacterial adhesin CbpA binds LR by a surface exposed loop distinct from that binding to the polymeric immunoglobulin receptor in the nasopharynx. Recently NanA was suggested to also promote pneumococcal adherence to brain endothelial cells through its laminin G-like lectin domain (Uchiyama et al. 2009). Once binding occurs to the vascular wall, the bacteria resist blood flow and activate underlying endothelial cells, specifically increasing the amount of PAFr on the endothelial surface (Fillon et al. 2006). PAFr then engages phosphorylcholine on the cell wall and translocates the bacteria across the endothelium intracellularly allowing passage from blood into brain. Mice lacking PAFr or bacteria deficient in CbpA do not develop meningitis even at very high titer bacteremia. Antibodies to CbpA are protective against meningitis across several species of bacteria.

\section{Meningitis as a Model of Inflammatory Damage}

Bacterial multiplication in the CSF space is fulminant as there are no innate defenses in this compartment. Thus, brain damage can be clearly tracked over time as a function of the interplay between bacterial components and the host response. The bacterial components responsible for the signs and symptoms of disease have been mapped by fractionating the pneumococcus, individually instilling pieces into the CSF space, and following inflammation and injury (Tuomanen et al. 1985). The hallmarks of meningitis are recruitment of leukocytes, bloodbrain barrier permeability as measured by increased CSF protein, and vascular dysregulation, leading to increased intracranial pressure. This symptom complex can be recapitulated by instilling only components of the pneumococcal cell wall or toxins in the absence of living bacteria. The significance of this finding is twofold: First, cell wall and toxin interactions that drive inflammation are key to injury and second, antibiotics cause lysis and the release of cell wall components which, in the first few doses, increase CSF inflammation. This provides the rationale for mitigating damage to host cells by decreasing the inflammatory response during antibiotic therapy (Tuomanen et al. 1987). Blocking leukocyte invasion and subsequent inflammation decreases brain edema, intracranial pressure, blood flow alterations, and neuronal damage (Tuomanen et al. 1989; Weber et al. 1995). Although the complete absence of TLR2 or MyD88 in mice leads to higher mortality with bacterial overgrowth (Koedel 2009), down-modulation of downstream signals has been shown to be beneficial, including targeting MAP kinases, NF-кB (Koedel et al. 2010), and pro- and anti-inflammatory cytokines (Saukkonen et al. 1990) as well as chemokines. In animal models, survival and burden of sequelae is improved by using anti-inflammatory agents together with antibiotics (Braun and Tuomanen 1999), including dexamethasone (Odio et al. 1991), antileukocyte agents (antiselectins or anti-CD18 integrin (Tuomanen et al. 1989), antimatrix metalloproteases, or inhibitors of nitric oxide.

The details of the host-pathogen interaction in the CSF have provided an excellent example of the overall picture of host response elements in Gram-positive disease. During the inflammatory response, neuronal toxicity is observed in two waves (Fig. 4). Direct toxin-mediated neuronal death occurs early in sepsis mediated by the release and penetration of the blood-brain barrier by pneumolysin and hydrogen peroxide (Braun et al. 2002; Weber and Tuomanen 2007). Approximately half of neuronal death is toxin mediated and is caspase independent. Later, during the host response to cell wall debris, indirect damage causes apoptosis of neurons and glia as a bystander effect (Mitchell et al. 2004). As leukocytes and serum components appear in the CSF over hours, bacterial peptidoglycan and teichoic acid bind to TLR2 that then leads to activation NF- $\mathrm{KB}$ (Yoshimura et al. 1999; Orihuela et al. 2006). Small- 


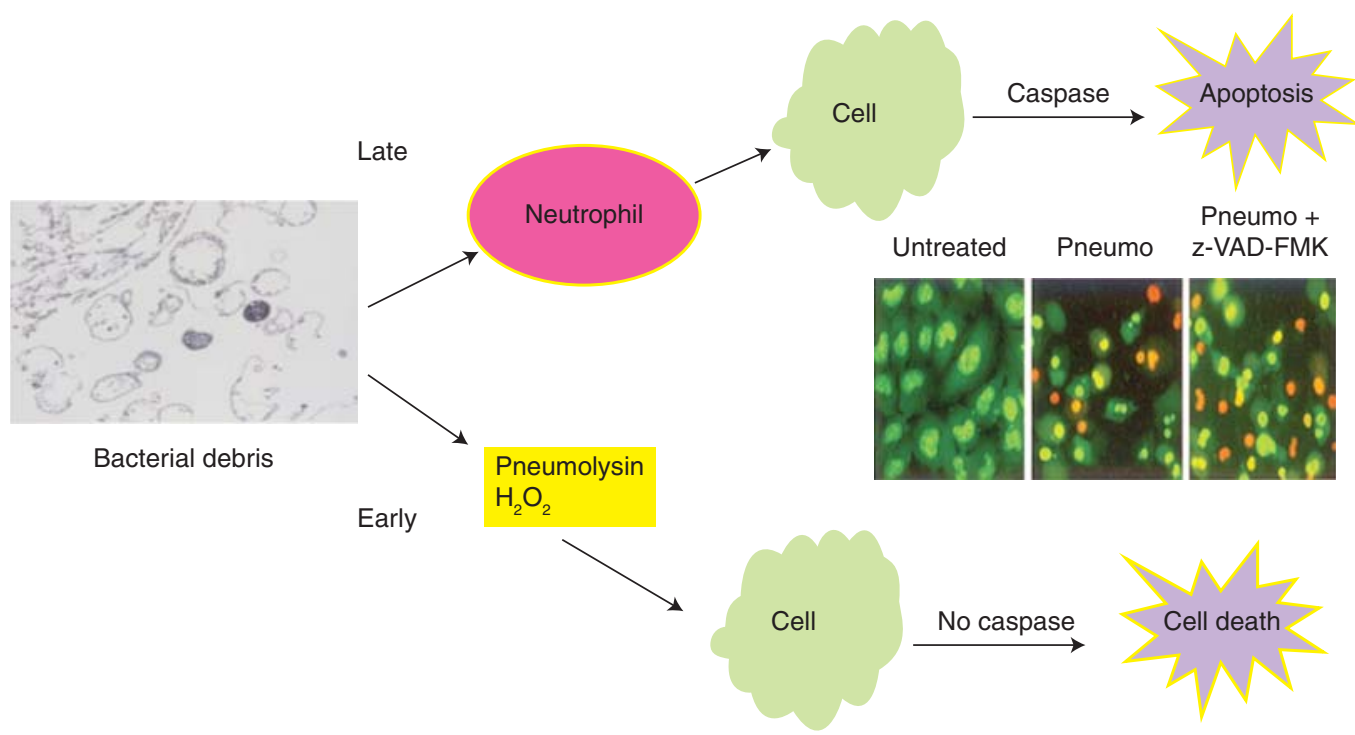

Figure 4. Host cell damage by pneumococcal components. During the inflammatory response, host cells are subjected to bacterial and host-derived toxic stimuli. Early in the course of disease, the bacteria produce the potent pore-forming cytotoxin pneumolysin and copious amounts of hydrogen peroxide, both of which kill host cells independent of caspases. Later in the course of the inflammatory response, when cell wall debris has induced neutrophil recruitment, host cells undergo caspase-dependent apoptosis. The caspase inhibitor z-VADFMK attenuates only half of the damage in infected tissues (inset: orange, dead cells; green, live cells).

er cell wall-derived muramyl peptides bind to NOD proteins. The accumulation of leukocytes is hastened by activation of the chemokine/cytokine cascade, the complement cascade, and the coagulation cascade. The damage caused by the host inflammatory response is greatest in the hippocampus where neuronal apoptosis is driven by caspase-dependent pathways (Braun et al. 1999). Oxidative damage from host-derived free radicals amplifies tissue damage (Braun et al. 2002; Hoffmann et al. 2006).

\section{CONCLUDING REMARKS}

The pneumococcus is the classic Gram-positive extracellular bacterial pathogen. It universally colonizes the nasopharynx and is the major cause of pneumonia, sepsis, and meningitis, causing more morbidity and mortality worldwide than any other infection. Its microbial physiology has revealed the discovery of DNA, the structure and assembly of Gram-positive peptidoglycan, the processes of quorum sensing, autolysis and transformation, and the first
Gram-positive genome sequence. It led to the deployment of polysaccharide vaccines and an understanding of antibiotic resistance. Study of the pneumococcus mapped out the basic interplay between innate invasion and innate immunity for the major infections of childhood. Phosphorylcholine, present on nearly all respiratory pathogens, interacts with PAFr for invasion of the respiratory tract, and is counteracted by CRP and surfactant. Meningeal pathogens recognize the blood-brain barrier by interactions with laminin receptor on the vascular endothelium. Gram-positive teichoic acids and peptidoglycan are recognized as PAMPs by TLR 2 and Nod2, DNA by TLR9. Pneumolysin is a pore-forming, cholesterol-dependent cytolysin. The inflammatory response to pneumococci, one of the most potent in medicine, underlies both protection and host cell damage and this understanding has lead to the clinical use of anti-inflammatory agents to improve the outcome of disease. In virtually every aspect of the infectious process, the pneumococcus has set the rules of the Gram-positive bacterial path- 
ogenesis game. Yet more details of why a pneumococcal invasion ultimately kills the host are still needed and will make a major impact on world health. Current challenges include developing a universal vaccine that the bacteria will not be able to circumvent by transformation and improving the outcome of infection by balancing inflammation with bacterial death during antibiotic therapy.

\section{ACKNOWLEDGMENTS}

E.I.T. is supported by National Institutes of Health grants R01 AI-27913 and U54 HL070590, the PATH Foundation, and the American Lebanese Syrian Associated Charities. B.H.N. is supported by the Swedish Research Council, Torsten and Ragnar Söderbergs Foundation, ALF-bidrag from Stockholm City Council, EU project Pneumopath with the 7th Framework Program, and VINNOVA.

\section{REFERENCES}

Albiger B, Dahlberg S, Sandgren A, Wartha F, Beiter K, Katsuragi H, Akira S, Normark S, Henriques-Normark B. 2007. Toll-like receptor 9 acts at an early stage in host defence against pneumococcal infection. Cell Microbiol 9: 633-644.

Austrian R. 1981. Pneumococcus: The first one hundred years. Rev Infect Dis 3: 183-189.

Avery OT, Macleod CM, McCarty M. 1944. Studies on the chemical nature of the substance inducing transformation of pneumococcal types: Induction of transformation by a desoxyribonucleic acid fraction isolated from pneumococcus type III. J Exp Med 79: 137-158.

Bagnoli F, Moschioni M, Donati C, Dimitrovska V, Ferlenghi I, Facciotti C, Muzzi A, Giusti F, Emolo C, Sinisi A, et al. 2008. A second pilus type in Streptococcus pneumoniae is prevalent in emerging serotypes and mediates adhesion to host cells. J Bacteriol 190: 5480-5492.

Barocchi M, Ries J, Zogaj X, Albiger B, Kanth A, Dahlberg S, Moschioni M, Masignani V, Hultenby K, von Euler A, et al. 2006. A pneumococcal pilus influences virulence and host inflammatory responses. Proc Natl Acad Sci 103: 2857-2862.

Bean B, Tomasz A. 1977. Choline metabolism in pneumococci. J Bacteriol 130: 571-574.

Bergmann S, Hammerschmidt S. 2006. Versatility of pneumococcal surface proteins. Microbiology 152: 295-303.

Bergmann S, Rohde M, Chhatwal GS, Hammerschmidt S. 2001. $\alpha$-Enolase of Streptococcus pneumoniae is a plas$\min$ (ogen)-binding protein displayed on the bacterial cell surface. Mol Microbiol 40: 1273-1287.
Berry AM, Paton JC. 2000. Additive attenuation of virulence of Streptococcus pneumoniae by mutation of the genes encoding pneumolysin and other putative pneumococcal virulence proteins. Infect Immun 68: 133-140.

Berry AM, Yother J, Briles DE, Hansman D, Paton JC. 1989. Reduced virulence of a defined pneumolysin-negative mutant of Streptococcus pneumoniae. Infect Immun 57: 2037-2042.

Boulnois GJ, Paton JC, Mitchell TJ, Andrew PW. 1991. Structure and function of pneumolysin, the multifunctional, thiol-activated toxin of Streptococcus pneumoniae. Mol Microbiol 5: 2611-2616.

Braathen R, Sandvik A, Berntzen G, Hammerschmidt S, Fleckenstein B, Sandlie I, Brandtzaeg P, Johansen F, Lauvrak V. 2006. Identification of a polymeric Ig receptor binding phage-displayed peptide that exploits epithelial transcytosis without dimeric IgA competition. J Biol Chem 281: 7075-7081.

Braun JS, Tuomanen EI. 1999. Molecular mechanisms of brain damage in bacterial meningitis. Adv Pediatr Infect Dis 14: 49-71.

Braun JS, Novak R, Herzog KH, Bodner SM, Cleveland JL, Tuomanen EI. 1999. Neuroprotection by a caspase inhibitor in acute bacterial meningitis. Nat Med 5: 298-302.

Braun JS, Sublett JE, Freyer D, Mitchell TJ, Cleveland JL, Tuomanen EI, Weber JR. 2002. Pneumococcal pneumolysin and $\mathrm{H}_{2} \mathrm{O}_{2}$ mediate brain cell apoptosis during meningitis. J Clin Invest 109: 19-27.

Briles DE, Nahm M, Schroer K, Davie J, Baker P, Kearney J, Barletta R. 1981. Antiphosphocholine antibodies found in normal mouse serum are protective against intravenous infection with type 3 Streptococcus pneumoniae.J Exp Med 153: 694-705.

Briles DE, Crain MJ, Gray BM, Forman C, Yother J. 1992. Strong association between capsular type and virulence for mice among human isolates of Streptococcus pneumoniae. Infect Immun 60: 111-116.

Brouwer M, de Gans J, Heckenberg S, Zwinderman A, van der Poll T, van de Beek D. 2009. Host genetic susceptibility to pneumococcal and meningococcal disease: A systematic review and meta-analysis. Lancet Infect Dis 9: $31-44$.

Brown JS, Hussell T, Gilliland SM, Holden DW, Paton JC, Ehrenstein MR, Walport MJ, Botto M. 2002. The classical pathway is the dominant complement pathway required for innate immunity to Streptococcus pneumoniae infection in mice. Proc Natl Acad Sci 99: 16969-16974.

Brueggemann A, Peto T. 2004. Temporal and geographic stability of the serogroup-specific invasive disease potential of Streptococcus pneumoniae in children. Infect Dis 190: $1203-1211$.

Canvin JR, Marvin AP, Sivakumaran M, Paton JC, Boulnois GJ, Andrew PW, Mitchell TJ. 1995. The role of pneumolysin and autolysin in the pathology of pneumonia and septicemia in mice infected with a type 2 pneumococcus. J Infect Dis 172: 119-123.

Centers for Disease Control and Prevention. 2008. Progress in introduction of pneumococcal conjugate vaccine worldwide. MMWR Morb Mortal Wkly Rep 57: 11481151.

Cohen JM, Khandavilli S, Camberlein E, Hyams C, Baxendale HE, Brown JS. 2011. Protective contributions against 
The Pneumococcus

invasive Streptococcus pneumoniae pneumonia of antibody and Th17-cell responses to nasopharyngeal colonisation. PLoS ONE 6: e25558.

Croucher N, Harris S, Fraser C, Quail M, Burton J, van der Linden M, McGee L, von Gottberg A, Song J, Ko K, et al. 2011. Rapid pneumococcal evolution in response to clinical interventions. Science 331: 430-434.

Cundell DR, Gerard NP, Gerard C, Idanpaan-Heikkila I, Tuomanen EI. 1995. Streptococcus pneumoniae anchor to activated human cells by the receptor for platelet-activating factor. Nature 377: 435-438.

Dagerhamn J, Blomberg C, Browall S, Sjöström K, Morfeldt E, Henriques-Normark B. 2008. Determination of accessory gene patterns predicts the same relatedness among strains of Streptococcus pneumoniae as sequencing of housekeeping genes does and represents a novel approach in molecular epidemiology. J Clin Microbiol 46: 863-868.

Davis K, Nakamura S, Weiser JN. 2011. Nod2 sensing of lysozyme-digested peptidoglycan promotes macrophage recruitment and clearance of $S$. pneumoniae colonization in mice. J Clin Invest 121: 3666-3676.

Doerschuk C, Tasaka S, Wang Q. 2000. CD11/CD18-dependent and -independent neutrophil emigration in the lungs: How do neutrophils know which route to take? Am J Respir Cell Mol Biol 23: 133-136.

Fälker S, Nelson AL, Morfeldt E, Jonas K, Hultenby K, Ries J, Melefors O, Normark S, Henriques-Normark B. 2008. Sortase mediate assembly and surface topology of adhesive pneumococcal pili. Mol Microbiol 70: 595-607.

Fillon S, Soulis K, Rajasekaran S, Benedict-Hamilton $\mathrm{H}$, Radin JN, Orihuela CJ, El Kasmi KC, Murti G, Kaushal D, Gaber MW, et al. 2006. Platelet-activating factor receptor and innate immunity: Uptake of Gram-positive bacterial cell wall into host cells and cell-specific pathophysiology. J Immunol 177: 6182-6191.

Girardin S, Boneca I, Viala J, Chamaillard M, Labigne A, Thomas G, Philpott D, Sansonetti P. 2003. Nod2 is a general sensor of peptidoglycan through muramyl dipeptide (MDP) detection. J Biol Chem 8: 8869-8872.

Gosink KK, Mann ER, Guglielmo C, Tuomanen EI, Masure H. 2000. Role of novel choline binding proteins in virulence of Streptococcus pneumoniae. Infect Immun 68: 5690-5695.

Gould JM, Weiser JN. 2002. The inhibitory effect of C-reactive protein on bacterial phosphorylcholine plateletactivating factor receptor-mediated adherence is blocked by surfactant. J Infect Dis 186: 361-371.

Griffith F. 1928. The significance of pneumococcal types. J Hyg (Lond) 27: 113-159.

Hammerschmidt S, Talay SR, Brandtzaeg P, Chhatwal GS. 1997. SpsA, a novel pneumococcal surface protein with specific binding to secretory immunoglobulin A and secretory component. Mol Microbiol 25: 1113-1124.

Hava DL, Camilli A. 2002. Large-scale identification of serotype 4 Streptococcus pneumoniae virulence factors. $\mathrm{Mol}$ Microbiol 45: 1389-1406.

Hiller NLAA, Powell E, Martin DP, Eutsey R, Earl J, Janto B Boissy RJ, Hogg J, Barbadora K, Sampath R, et al. 2010. Generation of genic diversity among Streptococcus pneumoniae strains via horizontal gene transfer during a chronic polyclonal pediatric infection. PLoS Pathog 6: e1001108.

Hoffmann O, Zweigner J, Smith SH, Freyer D, Mahrhofer C, Dagand E, Tuomanen EI, Weber JR. 2006. Interplay of pneumococcal hydrogen peroxide and host-derived nitric oxide. Infect Immun 74: 5058-5066.

Högberg L, Geli P, Ringberg H, Melander E, Lipsitch M, Ekdahl K. 2007. Age- and serogroup-related differences in observed durations of nasopharyngeal carriage of penicillin-resistant pneumococci. J Clin Microbiol 45: 948-952.

Izoré T, Contreras-Martel C, El Mortaji L, Manzano C, Terrasse R, Vernet T, Di Guilmi AM, Dessen A. 2010. Structural basis of host cell recognition by the pilus adhesin of Streptococcus pneumoniae. Structure 18: 106-115.

Jensch I, Gámez G, Rothe M, Ebert S, Fulde M, Somplatzki D, Bergmann S, Petruschka L, Rohde M, Nau R, et al. 2010. PavB is a surface-exposed adhesin of Streptococcus pneumoniae contributing to nasopharyngeal colonization and airways infections. Mol Microbiol 77: 22-43.

Kadioglu A, Taylor S, Iannelli F, Pozzi G, Mitchell TJ, Andrew PW. 2002. Upper and lower respiratory tract infection by Streptococcus pneumoniae is affected by pneumolysin deficiency and differences in capsule type. Infect Immun 70: 2886-2890.

Koedel U. 2009. Toll-like receptors in bacterial meningitis. Curr Top Microbiol Immunol 336: 15-40.

Koedel U, Klein M, Pfister H. 2010. Modulation of brain injury as a target of adjunctive therapy in bacterial meningitis. Curr Infect Dis Rep 12: 266-273.

Kolberg J, Aase A, Bergmann S, Herstad T, Rødal G, Frank R, Rohde M, Hammerschmidt S. 2006. Streptococcus pneumoniae enolase is important for plasminogen binding despite low abundance of enolase protein on the bacterial cell surface. Microbiology 152: 1307-1317.

Lau GW, Haataja S, Lonetto M, Kensit SE, Marra A, Bryant AP, McDevitt D, Morrison DA, Holden DW. 2001. A functional genomic analysis of type 3 Streptococcus pneumoniae virulence. Mol Microbiol 40: 555-571.

Lin C. 2010. Summary of invasive pneumococcal disease burden among children. Vaccine 28: 7589-7605.

Littmann M, Albiger B, Frentzen A, Normark S, HenriquesNormark B, Plant L. 2009. Pneumolysin expression allows evasion of human dendritic cell responses to Streptococcus pneumoniae. EMBO Mol Med 1: 211-222.

Löfling J, Vimberg V, Battig P, Henriques-Normark B. 2011. Cellular interactions by LPxTG-anchored pneumococcal adhesins and their streptococcal homologues. Cell Microbiol 13: 186-197.

Lu Y, Gross J, Bogaert D, Finn A, Bagrade L, Zhang Q, Kolls J, Srivastava A, Lundgren A, Forte S, et al. 2008. Interleukin-17A mediates acquired immunity to pneumococcal colonization. PLoS Pathog 4: e1000159.

Malley R, Henneke P, Morse SC, Cieslewicz MJ, Lipsitch M, Thompson CM, Kurt-Jones E, Paton JC, Wessels MR, Golenbock DT. 2003. Recognition of pneumolysin by Toll-like receptor 4 confers resistance to pneumococcal infection. Proc Natl Acad Sci 100: 1966-1971.

Mann B, Orihuela C, Antikainen J, Gao G, Sublett J, Korhonen TET. 2006. Multifunctional role of choline binding 
protein $\mathrm{G}$ in pneumococcal pathogenesis. Infect Immun 74: $821-829$.

Mann B, van Opijnen T, Wang J, Obert C, Wang YD, Carter R, McGoldrick DJ, Ridout G, Camilli A, Tuomanen EI, et al. 2012. Control of virulence by small RNAs in Streptococcus pneumoniae. PLoS Pathog 8: e1002788.

Marks M, Burns T, Abadi M, Seyoum B, Thornton J, Tuomanen E, Pirofski LA. 2007. Influence of neutropenia on the course of serotype 8 pneumococcal pneumonia in mice. Infect Immun 75: 1586-1597.

McCool, Weiser JN. 2002. The immune response to pneumococcal proteins during experimental human carriage. J Exp Med 195: 359-365.

Mitchell L, Smith SH, Braun JS, Herzog KH, Weber JR, Tuomanen EI. 2004. Dual phases of apoptosis in pneumococcal meningitis. J Infect Dis 190: 2039-2046.

Moreira LO, El Kasmi KC, Smith AM, Finkelstein D, Fillon S, Kim YG, Nunez G, Tuomanen E, Murray PJ. 2008. The TLR2-MyD88-NOD2-RIPK2 signalling axis regulates a balanced pro-inflammatory and IL-10-mediated antiinflammatory cytokine response to Gram-positive cell walls. Cell Microbiol 10: 2067-2077.

Munoz-Elias E, Marcano J, Camilli A. 2008. Isolation of Streptococcus pneumoniae biofilm mutants and their characterization during nasopharyngeal colonization. Infect Immun 76: 5049-5061.

Nakamura S, Davis KM, Weiser JN. 2011. Synergistic stimulation of type 1 interferons during influenza virus coinfection promotes Streptococcus pneumoniae colonization in mice. J Clin Invest 121: 3657-3665.

Nelson AL, Ries J, Bagnoli F, Dahlberg S, Fälker S, Rounioja S, Tschöp J, Morfeldt E, Ferlenghi I, Hilleringmann M, et al. 2007. RrgA is a pilus-associated adhesin in Streptococcus pneumoniae. Mol Microbiol 66: 329-40.

Nunes T, Sa-Leao R. 2005. Trends in drug resistance, serotypes, and molecular types of Streptococcus pneumoniae colonizing preschool-age children attending day care centers in Lisbon, Portugal: A summary of 4 years of annual surveillance. J Clin Microbiol 43: 1285-1293.

Odio C, Faingezicht I, Paris M, Nassar M, Baltodano A, Rogers J, Sáez-Llorens X, Olsen K, McCracken GJ. 1991. The beneficial effects of early dexamethasone administration in infants and children with bacterial meningitis. N Engl J Med 324: 1525-1531.

Orihuela CJ, Gao G, Francis KP, Yu J, Tuomanen EI. 2004. Tissue-specific contributions of pneumococcal virulence factors to pathogenesis. J Infect Dis 190: 1661-1669.

Orihuela CJ, Fillon S, Smith-Sielicki SH, El Kasmi KC, Gao G, Soulis K, Patil A, Murray PJ, Tuomanen EI. 2006. Cell wall-mediated neuronal damage in early sepsis. Infect Immun 74: 3783-3789.

Orihuela CJ, Mahdavi J, Thornton J, Mann B, Wooldridge KG, Abouseada N, Oldfield NJ, Self T, Ala'Aldeen DA, Tuomanen EI. 2009. Laminin receptor initiates bacterial contact with the blood brain barrier in experimental meningitis models. J Clin Invest 119: 1638-1646.

Paterson GK, Blue CE, Mitchell TJ. 2006. Role of two-component systems in the virulence of Streptococcus pneumoniae. J Med Microbiol 55: 355-363.

Radin JN, Orihuela CJ, Murti G, Guglielmo C, Murray PJ, Tuomanen EI. 2005. $\beta$-Arrestin 1 participates in platelet- activating factor receptor-mediated endocytosis of Streptococcus pneumoniae. Infect Immun 73: 7827-7835.

Rosenow C, Ryan P, Weiser JN, Johnson A, Fontan P, Ortqvist A, Masure HR. 1997. Contribution of novel cholinebinding proteins to adherence, colonization and immunogenicity of Streptococcus pneumoniae. Mol Microbiol 25: 819-829.

Rossjohn J, Feil SC, McKinstry WJ, Tweten RK, Parker MW. 1997. Structure of a cholesterol-binding, thiol-activated cytolysin and a model of its membrane form. Cell 89: 685-692.

Sanchez CJ, Shivshankar P, Stol K, Trakhtenbroit S, Sullam PM, Sauer K, Hermans PW, Orihuela CJ. 2010. The pneumococcal serine-rich repeat protein is an intra-species bacterial adhesin that promotes bacterial aggregation in vivo and in biofilms. PLoS Pathog 6: e1001044.

Sandgren A, Sjöström K, Olsson-Liljequist B, Christensson B, Samuelsson A, Kronvall G, Henriques Normark B. 2004. Effect of clonal and serotype-specific properties on the invasive capacity of Streptococcus pneumoniae. J Infect Dis 189: 785-796.

Sandgren A, Albiger B, Orihuela C, Tuomanen E, Normark S, Henriques-Normark B. 2005. Virulence in mice of pneumococcal clonal types with known invasive disease potential in man. J Infect Dis 192: 791-800.

Sato K, Quartey MK, Liebeler CL, Le CT, Giebink GS. 1996. Roles of autolysin and pneumolysin in middle ear inflammation caused by a type 3 Streptococcus pneumoniae strain in the chinchilla otitis media model. Infect Immun 64: $1140-1145$.

Saukkonen K, Sande S, Cioffe C, Wolpe S, Sherry B, Cerami A, Tuomanen E. 1990. The role of cytokines in the generation of inflammation and tissue damage in experimental Gram-positive meningitis. J Exp Med 171: 439448.

Sebert M, Palmer L, Rosenberg M, Weiser J. 2002. Microarray-based identification of htrA, a Streptococcus pneumoniae gene that is regulated by the CiaRH two-component system and contributes to nasopharyngeal colonization. Infect Immun 70: 4059-4067.

Sjöström K, Spindler C, Ortqvist A, Kalin M, Sandgren A Kuhlmann-Berenzon S, Henriques-Normark B. 2006. Clonal and capsular types decide whether pneumococci will act as a primary or opportunistic pathogen. Clin Infect Dis 42: 451-459.

Sjöström K, Blomberg C, Fernebro J, Dagerhamn J, Morfeldt E, Barocchi M, Andersson M, Browall S, Henriques F Rappuoli R, et al. 2007. Clonal success of piliated penicillin non-susceptible pneumococci. Proc Natl Acad Sci 104: $12907-12912$.

Sorek R, Cossart P. 2010. Prokaryotic transcriptomics: A new view on regulation, physiology and pathogenicity. Nat Rev Genet 11: 9-16.

Tettelin H, Nelson KE, Paulsen IT, Eisen JA, Read TD, Peterson S, Heidelberg J, DeBoy RT, Haft DH, Dodson RJ, et al. 2001. Complete genome sequence of a virulent isolate of Streptococcus pneumoniae. Science 293: 498-506.

Thornton JA, Durick-Eder K, Tuomanen EI. 2010. Pneumococcal pathogenesis: "Innate invasion" yet organ-specific damage. J Mol Med (Berl) 88: 103-107.

Tomasz A. 1965. Control of the competent state in pneumococcus by a hormone-like cell product: An example 
for a new type of regulatory mechanism in bacteria. $\mathrm{Na}$ ture 208: 155-159.

Tomasz A. 1997. Antibiotic resistance in Streptococcus pneumoniae. Clin Infect Dis 24: S85-S88.

Tong HH, Blue LE, James MA, DeMaria TF. 2000. Evaluation of the virulence of a Streptococcus pneumoniae neuraminidase-deficient mutant in nasopharyngeal colonization and development of otitis media in the chinchilla model. Infect Immun 68: 921-924.

Trappetti C, Ogunniyi A, Oggioni M, Paton J. 2011. Extracellular matrix formation enhances the ability of Streptococcus pneumoniae to cause invasive disease. PLoS ONE 6: e19844.

Tuomanen E, Liu H, Hengstler B, Zak O, Tomasz A. 1985. The induction of meningeal inflammation by components of the pneumococcal cell wall. J Infect Dis 151: 859-868.

Tuomanen E, Hengstler B, Rich R, Bray MA, Zak O, Tomasz A. 1987. Nonsteroidal anti-inflammatory agents in the therapy for experimental pneumococcal meningitis. $J$ Infect Dis 155: 985-990.

Tuomanen EI, Saukkonen K, Sande S, Cioffe C, Wright SD. 1989. Reduction of inflammation, tissue damage, and mortality in bacterial meningitis in rabbits treated with monoclonal antibodies against adhesion-promoting receptors of leukocytes. J Exp Med 170: 959-969.

Uchiyama S, Carlin A, Khosravi A, Weiman S, Banerjee A, Quach D, Hightower G, Mitchell T, Doran K, Nizet V. 2009. The surface-anchored NanA protein promotes pneumococcal brain endothelial cell invasion. J Exp Med 206: 1845-1852.

van Opijnen T, Bodi KL, Camilli A. 2009. Tn-seq: highthroughput parallel sequencing for fitness and genetic interaction studies in microorganisms. Nat Methods 6 767-772.
Weber JR, Tuomanen EI. 2007. Cellular damage in bacterial meningitis: An interplay of bacterial and host driven toxicity. J Neuroimmunol 184: 45-52.

Weber J, Angstwurm K, Bürger W, Einhäupl K, Dirnagl U. 1995. Anti ICAM-1 (CD 54) monoclonal antibody reduces inflammatory changes in experimental bacterial meningitis. J Neuroimmunol 63: 63-68.

Weber JR, Freyer D, Alexander C, Schroder NW, Reiss A, Kuster C, Pfeil D, Tuomanen EI, Schumann RR. 2003. Recognition of pneumococcal peptidoglycan: An expanded, pivotal role for LPS binding protein. Immunity 19: $269-279$.

Weiser JN, Austrian R, Sreenivasan PK, Masure HR. 1994. Phase variation in pneumococcal opacity: Relationship between colonial morphology and nasopharyngeal colonization. Infect Immun 62: 2582-2589.

Weiser JN, Bae D, Fasching C, Scamurra RW, Ratner AJ, Janoff EN. 2003. Antibody-enhanced pneumococcal adherence requires IgAl protease. Proc Natl Acad Sci 100: 4215-4220.

Whitney CG, Farley MM, Hadler J, Harrison LH, Bennett NM, Lynfield R, Reingold A, Cieslak PR, Pilishvili T, Jackson D, et al. 2003. Decline in invasive pneumococcal disease after the introduction of protein-polysaccharide conjugate vaccine. $N$ Engl J Med 348: 1737-1746.

Yoshimura A, Lien E, Ingalls RR, Tuomanen E, Dziarski R, Golenbock D. 1999. Cutting edge: Recognition of Grampositive bacterial cell wall components by the innate immune system occurs via Toll-like receptor 2. J Immunol 163: $1-5$.

Zhang JR, Mostov KE, Lamm ME, Nanno M, Shimida S, Ohwaki M, Tuomanen E. 2000. The polymeric immunoglobulin receptor translocates pneumococci across human nasopharyngeal epithelial cells. Cell 102: 827-837. 